\title{
Removal of lead, cadmium and zinc by waste tea leaves
}

\begin{abstract}
The solid waste of commercially available tea leaves of local produce were found to be good sorbents of metal ions, especially $\mathrm{Pb}$ (II), $\mathrm{Cd}$ (II) and $\mathrm{Zn}$ (II) ions. The extent of adsorption depends on $\mathrm{pH}$, ionic strength, metal concentration, substrate concentration, and the presence of interfering ions and surfactants. Among the various types of surfactants studied, cetyl trimethylammonium bromide severely hindered the metal uptake while Triton X1OO interfered mildly. Initial enhancement of $\mathrm{Pb}$ (II) and $\mathrm{Zn}$ (II) uptake was observed in the presence of small amount of sodium dodecyl sulphate. The enhancement effect decreased as the anionic surfactant concentration increased. Metal concentration dependence curves can be described by a Langmuir isotherm. Adsorption capacities of tea leaves were found to be 0.38 , 0.28 and $0.18 \mathrm{mmole} / \mathrm{g}$ for $\mathrm{Pb}, \mathrm{Cd}$ and $\mathrm{Zn}$ respectively.Column experiments revealed near $100 \%$ efficiency for metal removal of as much as $100 \mathrm{ppm} \mathrm{Pb}(11)$ ion at $\mathrm{pH} 6$, using $1.8 \mathrm{~g}$ waste tea leaves and flow rate of $25 \mathrm{ml} / \mathrm{min}$. The relative affinities of metal ions towards waste tea leaves is in the order of $\mathrm{Pb}>\mathrm{Cd}>\mathrm{Zn}$.
\end{abstract}

Keyword: Solid waste management; Tea; Waste water management; Adsorption 